\title{
Testicular Metastasis of a Prostatic Adenocarcinoma: A Case Report and a Review of the Literature
}

\section{Bienvenue Désiré $\mathrm{Ky}^{1}$, Gnimdou Botcho ${ }^{1}$, Adama Ouattara ${ }^{2}$, Aimé Sosthène Ouédraogo ${ }^{3}$ Klifford Klovis Kaboré ${ }^{1}$, Dieudonné Kambou ${ }^{1}$, Fasnéwindé Kaboré ${ }^{1}$}

${ }^{1}$ Urology Department of the University Teaching Hospital Yalgado Ouedraogo, Burkina Faso.

${ }^{2}$ Urology Department of the University Teaching Hospital Souro Sanou, Burkina Faso.

${ }^{3}$ Anatomopathology Department of the University Teaching Hospital Yalgado Ouedraogo. gabotcho@gmail.com; kaborefamd@icloud.com; sostheneaime@yahoo.fr

*Corresponding Author: Gnimdou Botcho, Urology Department of the University Teaching Hospital Yalgado Ouedraogo, Burkina Faso.

\section{Abstract}

The incidence of testicular cancer metastasis during autopsies is approximately 2.5\%. Although the majority of secondary testicular metastases are due to prostate cancer, only a few patients with prostate cancer will develop clinical manifestations of testicular metastases. We report the case of a patient with metastatic prostate cancer at the testicular level, diagnosed following the presence of a right testicular mass on palpation. This was an 68-year-old patient who had lower urinary tract symptoms with a total PSA of $751.7 \mathrm{ng} / \mathrm{ml}$. Advanced prostate cancer (T4N1M1c) has been diagnosed. He was then treated with androgen deprivation by surgical castration. He underwent bilateral orchiectomy and histopathological examination of the part reported adenocarcinomatous metastasis of the right testicle.

Keywords: testicular metastasis; cancer; prostate; orchiectomy

\section{INTRODUCTION}

The incidence of testicular cancer metastasis during autopsies is approximately $2.5 \%$, including nonneoplastic deaths [1].

Most secondary testicular metastases usually originate from distant primary sites including the lungs, prostate and gastrointestinal tract [2].

Testicular metastases occur in about $4 \%$ of prostate cancer cases and are often detected incidentally after orchiectomy in the treatment of advanced prostate cancer [3].

Generally, metastases from prostate cancer to pelvic lymph nodes, bones, lungs and liver occur at an advanced stage; however, few of these patients will clinically manifest testicular metastases [4].
Testicular metastases of prostate cancer are most often unilateral, but there are bilateral, synchronous or metachronous locations, which are infrequent [5].

We report the case of a metastatic prostate cancer patient at the testicular level in whom the diagnosis was based on the presence of a palpable mass in the right testicle.

\section{OBSERVATION}

It was an 68-year-old patient with a history of undocumented urinary tract surgery admitted to our Urology Department for dysuria with urinary jet weakness and drip urination; pollakiuria (03 nocturnal lifts) and urinary burns. He also had a painless right scrotal hemisphere swelling with an ipsilateral hydrocele of average abundance (figure 1). 
Testicular Metastasis of a Prostatic Adenocarcinoma: A Case Report and a Review of the Literature

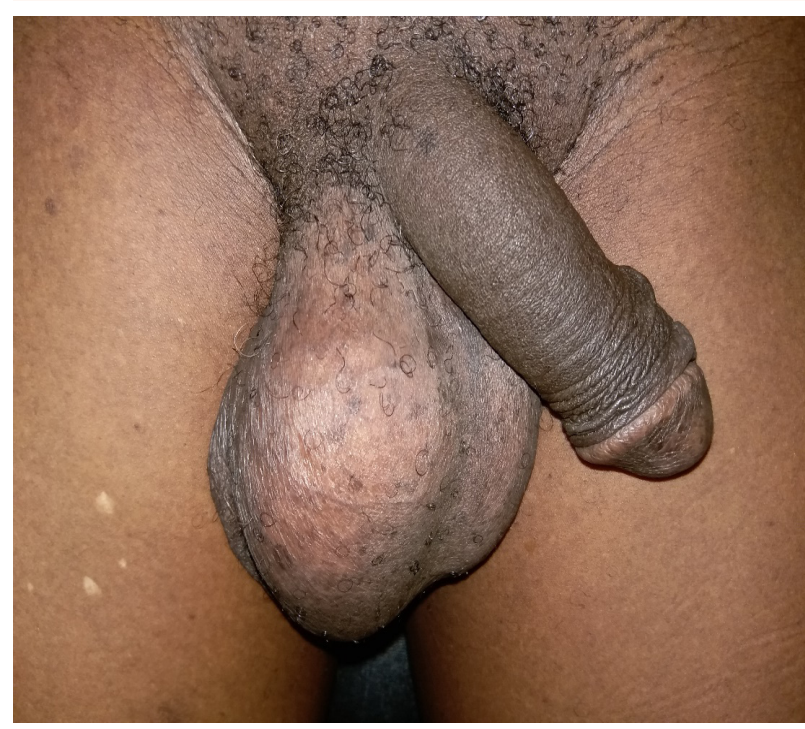

Figure 1. Right scrotal swelling

The clinical examination at admission noted, a large right testicular tumor, firm with irregular contours with good general condition.

The digital rectal examination found an enlarged nodular prostate, hard, irregular, painless and a major elevation of total PSA to $751.7 \mathrm{ng} / \mathrm{ml}$. Prostatic biopsies confirmed the presence of prostatic adenocarcinoma, Gleason $6(3+3)$, group 1 with perineural sheathing (Figure 1), all cores were positive 08 out of 08 .

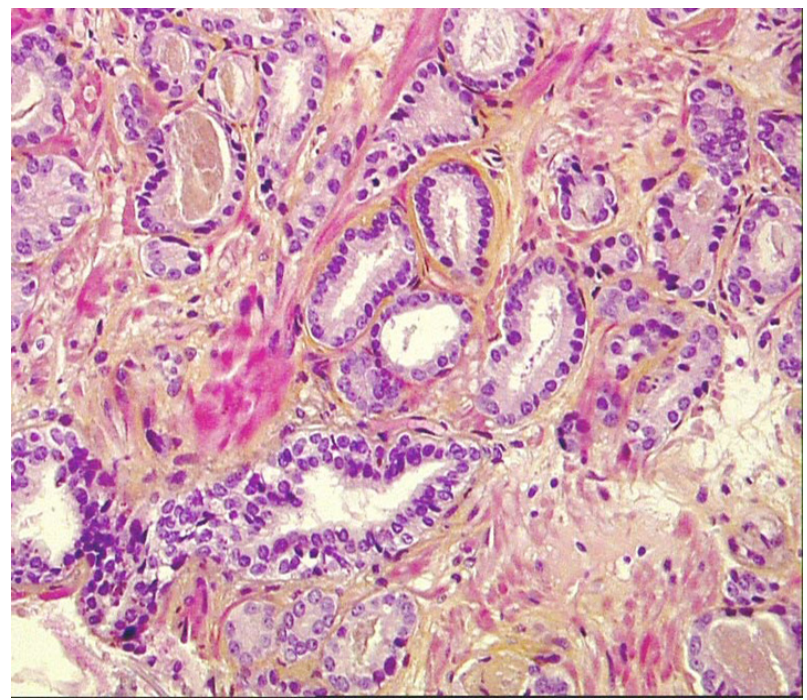

Figure 2. Histological appearance of prostatic adenocarcinoma, Gleason $6(3+3)$. HES coloring.

The uroculture was sterile and the normal renal outcome (creatinemia and uremia). Markers of testicular tumors were normal (alpha foeto-protein at $6.57 \mathrm{ng} / \mathrm{ml}$, Lactico Dehydrogenase at $165 \mathrm{U} / \mathrm{l}$ and beta-human-choriogonadotrophin at $06 \mathrm{mIU} / \mathrm{ml}$ ). The extension assessment (thoraco-abdominopelvic CT and bone scan) showed liver and bone metastases (pelvis and dorso-lumbar spine) and retroperitoneal lymph nodes. The diagnosis retained in this patient was advanced T4N1M1c prostate cancer.

Our patient was then treated with androgen deprivation by surgical castration. Bilateral orchiectomy was done. Histopathological examination of the specimens showed a right testicle with histologic appearance of metastasis of prostatic adenocarcinoma (Figures 2 and 3) and a normal left testicle. In the post operative period, at 02 months the total PSA level dropped to $15.40 \mathrm{ng} / \mathrm{ml}$ with a significant improvement of the symptoms of the lower urinary tract.

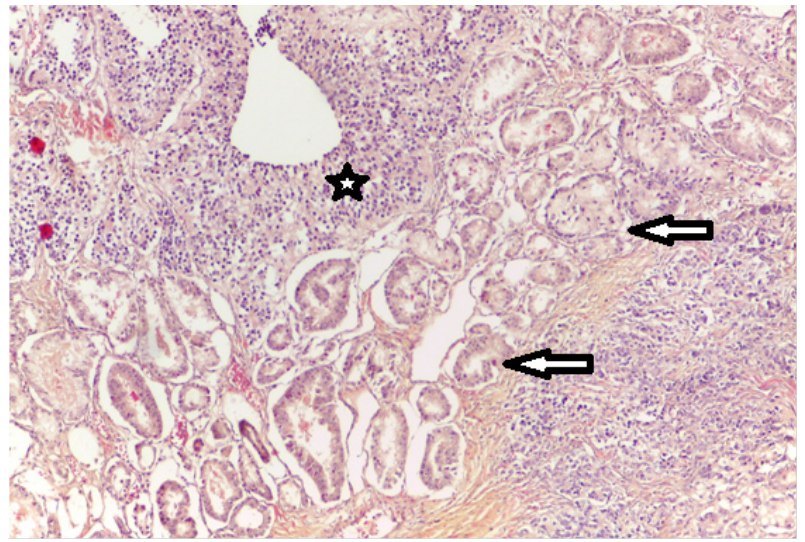

Figure 3. Testicular metastasis of prostatic adenocarcinoma G 100, HES staining. Testicular tissue (star) destroyed by prostatic adenocarcinomatous proliferation (Arrows)

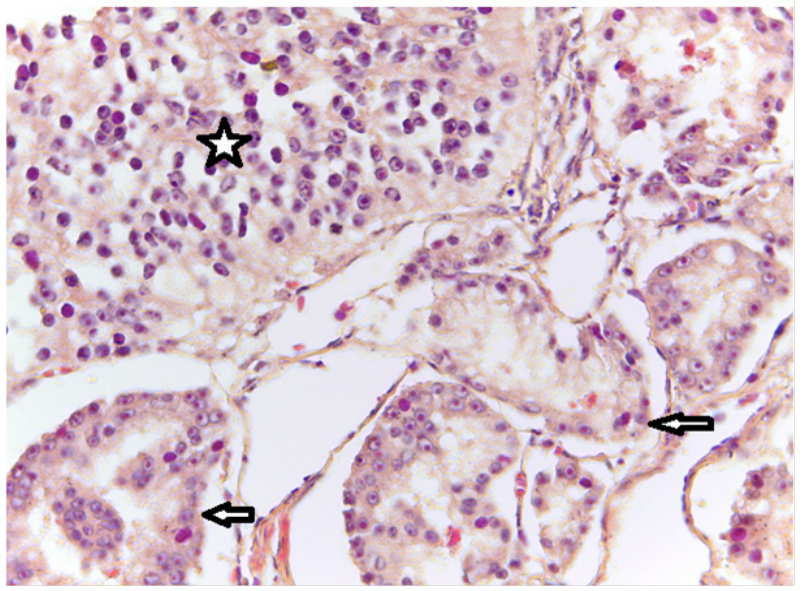

Figure 4. Testicular metastasis of prostatic adenocarcinoma G 400, HES staining. Detail at high magnification showing Sertoli cells (star) and prostatic carcinomatous glands (arrows) 
Testicular Metastasis of a Prostatic Adenocarcinoma: A Case Report and a Review of the Literature

\section{DISCUSSION}

The metastatic sites most commonly found in prostate cancer are bones (84\%), distant lymph nodes (10.6\%), liver (10.2\%) and thorax (9.1\%) [6]. Testicular metastases are rare, the majority of which are incidental findings in $2-4 \%$ of orchiectomy specimens for hormone therapy for advanced prostate cancer [7]. Khannoussi [8] explained this scarcity of testicular metastases by the fact that the relatively low scrotal temperature, would inhibit the growth of the tumor cells, and thus the testicular secondary localizations.

The first case of prostate cancer with testicular metastasis was reported by Semans in 1938 [9]. In two autopsy examinations, Dutt\& al. [2] reported that only $0.02 \%$ to $2.5 \%$ of prostate cancer patients had testicular metastasis. Thus, in an autopsy series of 24000 cases, Pienkos and Jablokow [10] noted $0.06 \%$ of prostate testicular metastases. Price and Mostophi [11] studying 1600 testicular tumors, found 38 metastatic tumors, 12 of which were of prostatic origin. Approximately $04 \%$ of patients with testicular metastases were diagnosed by chance after bilateral orchiectomy for surgical castration [12].

Metastatic testicular involvement is by several pathways, the most important of which is the retrograde pathway in the vas deferens lumen, especially in patients with a single metastatic testicular site. Dissemination may also be by arterial, lymphatic, retrograde venous or direct local extension of the prostatic tumor [8]. In our case, the presence of lymphatic emboli on histological examination advocated for lympho-vascular extension. The integrity of the epididymis and vas deferens against retrograde infiltration.

Most patients with testicular metastasis tend to be older (around 60 and 70 years) than patients with primary testicular germ cell tumors. The majority of publications have focused on unilateral forms of testicular metastasis of prostate cancer, the same was true for our case, however bilateral forms have also been reported [13].

The clinical presentation is often asymptomatic and the discovery is fortuitous on the pieces of bilateral orchiectomies [13]. In our case the patient had a palpable testicular mass, which reminded us of a primary testicular tumor associated with prostate cancer. However, the mass proved to be metastatic in relation to prostate cancer. The discovery of a testicular mass in a patient beyond the age of 50 must lead to the search for a primary tumor, in particular a prostatic tumor [8]. In the case we report, the diagnosis was based solely on histological examination.

On the other hand, Khannoussi [8] had made the diagnosis on the histological and especially immunohistochemical basis. Immunohistochemistry would be justified in the elimination of a primitive testicular tumor pathology (negativity of the labeling by CD17, CD30, beta HCG, placental alkaline phosphatase, alpha foeto protein, octmer-binding transcription factor 3/4) and to affirm the metastatic character of the lesion.

In patients with testicular metastasis of prostate cancer, survival after diagnosis is generally less than one year [14]. Lu \& al. [15] found an average survival of 12.8 months in patients with prostate cancer and 7.4 months in those with other forms of cancer. Nevertheless, in our case, a significant decrease in the total PSA level was observed after surgical castration; but testicular metastases can behave aggressively.

\section{CONCLUSION}

Testicular metastases of prostatic adenocarcinoma are rare. Their frequency is currently increasing. The existence of a testicular tumor in a man beyond the fifth decade, carrying a prostate cancer, should evoke the possibility of a metastatic localization. They are often asymptomatic and histologically discovered after orchiectomies.

\section{REFERENCES}

[1] Tiltman J: Metastatictumors in the testis. Histopathology 1979; 3: 31-37.

[2] Dutt N, AW Bates, Baithum SI. Secondary neoplasms of the male genital tract with different patterns of involvement in adults and children. Histopathology 2000; 37: 323-331.

[3] You SM, Reyes A, Maa A, Bhowmick D, LL Pisters, CA Pettaway, Lin S, Troncoso P, Logothetis CJ. Prostate carcinoma with testicular or 
Testicular Metastasis of a Prostatic Adenocarcinoma: A Case Report and a Review of the Literature

penilemetastases. Clinical, pathologic, and immunohistochemicalfeatures. Cancer 2002; 94: 2610-2617.

[4] Gunlusoy B, Arslan M, Selek E, Centinel M, Ayder AR, Cicek S. Case report: prostatic carcinoma with metastasis to the testicle. Int UrolNephrol 2004; 36: 63-64.

[5] Mobile K, AML Punga-Maole, JMM Kabongo, Kisile O. Bilateral testicularmetastasis of a prostate adenocarcinoma: ametachronous case with ACE increase. Ann. Afr. Med. 2011; 4 (2): 739-742.

[6] Gandaglia G, Abdollah F, Schiffmann J, et al. Distribution of metastatic sites in patients with prostate cancer: A population-basedanalysis. Prostate. 2014; 74 (2): 210-6.

[7] Haupt B, Ro JY, Ayala AG, Zhai J. Metastatic prostatic carcinoma to testis: Histological features mimickinglymphoma. Int J Clin ExpPathol. 2009; 2: 104-07.

[8] Khannoussi BE, Bouraoui K, Ozone F, Roux JJ, Dieny A, Bondil P, Pocachard P. A new observation of a testicularmetastasis of aprostaticadenocarcinoma: Diagnostic and etiopathogenic aspects. Andrology 2007; 17 (3): 288-291.
[9] Semans JH. Carcinoma of the prostate with metastases to the testes. J Urol.1938; 40: 524.

[10] Pienkos EA, Jablokow VR. Secondary testicular tumors. Cancer 1972; 30: 481-485.

[11] Price EB Jr, Mostofi FK. Secondarycarcinoma of the testis. Cancer 1957; 10: 592-5.

[12] Kwon SY, Jung HS, Lee JG, SH Choi, Kwon TG, Kim TH. Solitary Testicular Metastasis of Prostate Cancer Mimicking Primary Testicular Cancer. Korean J Urol 2011; 52: 718-720.

[13] Sampathrajan S, Garg G, Gupta S, Sahay SC, DE. Incidentally Detected Testicular Metastasis in a Case of Prostatic Adenocarcinoma. JCD. Research. 2015 ; 9 (12): 03-04.

[14] Kusaka A, Koie T, Yamamoto H, Hamano I, Yoneyama T, Hashimoto Y, Ohyama C, Tobisawa Y, Yoneyama T. Testicular Metastasis of Prostate Cancer: A Case Report. Case RepOncol 2014; 7: 643-647.

[15] Lu L, Kuo J, ATL Lin, Chang Y, Chen K, Pan C, LS Chang: Metastatictumors involving the testes. J Urol ROC. 2000; 11: 12-16.

Citation: Gnimdou Botcho, Fasnéwindé Kaboré, Aimé Sosthène Ouédraogo, et al. Testicular Metastasis of a Prostatic Adenocarcinoma: A Case Report and a Review of the Literature. Archives of Urology. 2019; 2(2): 5-8.

Copyright: (C) 2019 Gnimdou Botcho, Fasnéwindé Kaboré, Aimé Sosthène Ouédraogo, et al. This is an open access article distributed under the Creative Commons Attribution License, which permits unrestricted use, distribution, and reproduction in any medium, provided the original work is properly cited. 